\title{
The Effect of Contextual and Personal Factors on the Use of Probabilistic Recommenders in E-Markets
}

\author{
M.A. O’Hare*, J.G. Phillips and S. Moss
}

School of Psychology, Psychiatry, \& Psychological Medicine, Monash University, Australia

\begin{abstract}
E-markets of the future may extend to real-time, on-line auctions of, for example, real estate or antiques. To operate successfully in real-time e-markets, knowledge-based recommenders may become indispensable. Real-time emarket trading decisions typically take place in dynamic and uncertain environments in which high stakes, time pressure, multiple players, and feedback loops are key characteristics. A $2 \times 2 \times 2$ design was used in which risk, time pressure and availability of a probabilistic recommender were manipulated. The effect of the recommender on the confidence and performance of three groups of decision-makers (novices, journeymen and expert) was examined. Finally, deductive logic ability was assessed. 84 participants engaged in a laboratory-based computer simulation of a customized version of Blackjack that approximated a real-world e-market decision environment. Recommender use differed with expertise level. Novices were significantly more confident when the recommender was available and used its advice to avoid decision errors. The recommender did not alter the confidence of journeymen and experts but they used it to avoid errors as contextual factors became more complex. There were significant group differences in recommender use to improve strategic outcomes: recommender use enhanced experts' performance, damaged journeymen's and had little effect on novices'. In addition, deductive logic ability was significantly related to fewer decision errors. These results suggest that, to be effective in dynamic e-market environments, knowledge-based recommenders should be tailored to individual differences, particularly decision-makers' expertise and reasoning ability.
\end{abstract}

Keywords: Recommender, advice, decision making, risk, time pressure, expertise, deductive logic ability.

\section{INTRODUCTION}

Although e-commerce speeds up transactions, it also places an organization's competitors just another click away [1]. Therefore, e-organizations use recommenders to gain commercial leverage by adding "perceived value to the transaction" [2]. Recommenders assist consumers to navigate large product information spaces by narrowing the search and suggesting items of potential interest $[3,4]$. From a commercial perspective, recommenders boost sales by personalizing the web-site to suit customer's preferences, recommending additional, similar products (i.e. crossselling), and by building customer loyalty through individualized customer profiling [5]. Recommender systems have, therefore, become indispensable business tools that are "re-shaping the world of e-commerce" [5].

To operate successfully in real-time e-markets, individualized, knowledge-based recommenders may become indispensable. However, traditional preferencebased recommenders would be insufficient in an e-market environment because knowledge-based recommenders would operate as semi-autonomous e-agents providing personalized advice or representing the user in the virtual marketplace [6]. Confidence or trust in the quality of the recommender's advice is central to this e-relationship, particularly in uncertain environments in which financial risk is involved with use of the technology [7].

*Address correspondence to this author at the School of Psychology, Psychiatry, \& Psychological Medicine, Monash University, Australia;

E-mail: Mary.OHare@med.monash.edu.au
Due to the relatively low cost, instantaneous transmission of information world-wide via the internet, 'word of mouse' may become the predominant market force of the future [8]. Therefore, it is in e-organizations' interests to ensure that recommenders are matched to customers' requirements through individualized customer profiling. Because trust and use of a recommender are determined by results $[9,10]$, it is important to understand how characteristics of the recommender, the user, and the task interact to influence recommender use and decision outcomes.

Knowledge-based recommenders enhance users' decision quality by expanding their cognitive abilities [11]. According to the theory of bounded rationality [12], decision makers lack the resources to process all relevant information because of cognitive limitations, particularly those of short-term memory [13]. Consequently, less than optimal decision strategies are chosen [13]. This effect is exacerbated by time pressure [11]. Therefore, recommenders may be used to maintain optimum decision strategies under time pressure. Chu and Spires [14] found that, when selecting rental apartments, time-pressured participants used the recommender's functions to process information faster, thereby reducing cognitive load and effort. However, timeconstrained users accessed fewer of the recommender's alternatives suggesting that highly complex decision aids may not confer additional benefit under time pressure.

Bounded rationality theory, however, is concerned primarily with the effect of cognitive limitations on decision quality and does not explicitly consider the role of effort in decision making [11]. In addition, to improving decision quality, Chu and Spires [11] found that decision makers use 
recommenders according to a cost-benefit principle in which the relative cost (effort) associated with recommender use is traded off with the relative benefit (decision quality). Chu and Spires [11] found that, in some cases, decision makers were prepared to expend extra effort to use recommenders that improved accuracy. In contrast, Todd and Benbasat [15] report that computerized decision aids that required less effort than a more normative strategy, but conferred a similar benefit in terms of accuracy, were used. Overall, therefore, both quality and effort "play a joint role" in the use of recommenders [11], although the cost-benefit ratio appears to differ across studies.

Another critical aspect of the recommender which may influence its use is whether the recommender is a command or status aid [16]. A status decision aid provides information on the current state of the environment. In contrast, a command aid dispenses advice. Status and command recommenders support different parts of the decision process. A status recommender supports the identification of a problem whereas a command display supports action selection, thus eliminating the need for problem diagnosis [16]. In e-markets, command recommenders may be more beneficial than status recommenders because they support the action selection stage of decision making, thereby eliminating the need to process all relevant information in a time-constrained and risky environment.

In closed system environments where all contingencies can be anticipated, it would be impossible to better the advice recommended by command displays [17]. However, in probabilistic or open system environments (such as emarkets) where unanticipated events occur, a command decision aid will sometimes provide inaccurate advice [17]. Reliance on a probabilistic recommender often improves decision-making performance above that of unaided decision making [18,19]. However, users do not rely fully on probabilistic recommenders, probably due to inaccuracies. Therefore, the quality of their aided decision making is often less than the standard set by the recommender $[10,19,20]$. Therefore, it is important to understand the factors that influence the continued use of probabilistic recommenders despite their occasional inaccuracies.

Probabilistic command recommenders may be more beneficial in some environments than others, and this effect may be attenuated by task familiarity and level of user expertise. For example, Dexter et al., [18] reported that probabilistic command recommenders improved the quality of typical decision making among managerial operating room (OR) staff. In contrast, status recommenders did not confer any benefit on OR decision outcomes. Furthermore, decision-making unassisted by probabilistic command recommenders was no better than chance. When the probabilistic command recommender dispensed inaccurate advice, it was (appropriately) ignored. However, Sarter and Schroeder [16] found that use of probabilistic command aid to assist performance in an unfamiliar task in a high risk domain, adversely affected aspects of pilot performance, presumably because pilots were less willing to ignore its advice when it was inaccurate. However, this effect was attenuated by level of expertise - more experienced pilots' performance recovered faster from inaccurate advice.
A ubiquitous research finding is that decision aid neglect is more prevalent among users with greater domain-related knowledge [21], an effect commonly ascribed to overconfidence [20]. However, according to the theory of technological dominance [22], other critical factors, such as cognitive fit between the user and the decision aid, familiarity with the decision aid and task complexity influence expert decision makers' reliance on a recommender. Arnold, Collier, Leech and Sutton [23] provide empirical support for the cognitive fit component of this theory, that is, a skill mismatch between recommender and user results in poorer performance. Specifically, intelligent decision aids designed to elevate novice decision making to a level similar to that of an expert resulted in poorer decision making while aids matched to expert users' skill level resulted in enhanced decision making. Whitecotton [19] also reported differential expertise-related effects arising from the use of a probabilistic recommender. While the recommender enhanced the performance of financial forecasters above their baseline performance, it improved different aspects of performance according to the financial analysts' experience. Among experts (professional financial analysts), the recommender improved the calibration of forecasts while among less experienced forecasters (undergraduate and graduate MBA students) the recommender reduced the variation in forecasts.

The different expertise-related benefits conferred by probabilistic recommenders may be due to the development of competence. According to models of expertise, novice performance is characterized by explicit rules and an avoidance of gross errors while expert performance is characterized by a big picture approach based upon underlying abstract principles [24]. These two differing foci may underlie the differential benefit conferred by probabilistic recommenders.

User expertise may also interact with contextual variables to influence the use of probabilistic recommenders. Two key contextual variables that characterize e-markets, such as realtime e-auctions, are risk and time pressure. However, relatively few studies have examined the use of recommenders in risky and time-pressured environments [16].

A notable exception examined the effect of two types of recommenders (accurate and probabilistic) on pilot performance when dealing with ice build-up on an aeroplane's exterior during flight [16]. Ice build-up on an airplane's wings or tail is a potentially serious problem that can interfere with lift and stability, ultimately leading to midair stalling. Accurate recommenders improved pilot performance across the board. In contrast probabilistic recommenders, which were accurate $70 \%$ of the time, were detrimental to pilot's performance, although pilots who were familiar with the task recovered more quickly from decisions based on inaccurate advice. Therefore, user expertise may influence the efficacy of a probabilistic recommender in risky, time-pressured environments.

The likelihood of systematic processing of information by decision makers also seems to depend on individual differences rather than merely contextual factors, such as time pressure and risk level. Individuals with higher levels of deductive logic ability may adopt a more analytical approach 
to problem solving and engage in more systematic processing of information. It has been estimated that human error accounts for approximately $90 \%$ of industrial and system failures [25]. However, there is a lack of an extensive empirical body of knowledge detailing how or why errors occur, as well as the absence of an adequate body of theoretical knowledge to explain error occurrence [25]. The best way to interpret errors, therefore, may be as "failures of reasoning" [25]. The ability to reason, that is, to form conclusions based on incoming information, facilitates successful interaction with the environment [26]. Therefore, higher levels of logic ability should promote more successful decisions by reducing errors.

Logic ability is also related to expertise. Reasoning ability, which is central to intelligence [27], is associated with skill acquisition in the early stages of development $[28,29]$ while deliberate focused practice predicts expert performance $[30,31]$. Therefore, it is expected that deductive logic ability will be related to error occurrence among less experienced decision makers (i.e. novices and journeymen) but not experts.

The studies reviewed above assessed the role of domainspecific expertise on the use of probabilistic recommenders. Electronic consumers are unlikely to be professionals, however, they will have different levels of general decisionmaking expertise. Unfortunately, classification of general decision-making ability lacks a universal yardstick. Level of education may be a suitable criterion to grade decisionmaking performance. Level of education is significantly and positively associated with better decision making across a variety of market sectors [32] as well as being a significant predictor of later executive career success and amount of remuneration [33]. Applying the criteria of Ericsson et al., [31], education level provides a performance-based appraisal of expertise level which is preferable to an experiencerelated approach because experience may not necessarily lead to expertise [23]. For example, education level uses a successive hurdle method in which qualifications are gained following satisfactory performance to a particular standard. Furthermore, performance is rated by domain experts (examiners) and provides a form of peer acknowledgment. Therefore, level of education was deemed a suitable measure for classifying participants in the present study into three general decision-making categories - novices, journeymen and experts.

The aim of the present study was to determine (a) if a probabilistic recommender would confer benefit in an emarket environment (b) which contextual factors would affect recommender use and (3) which group of decisionmakers would benefit from the recommender. Therefore, this study examined the effect of contextual factors (risk and time pressure) on the use of a probabilistic, knowledge-based recommender among three groups of decision-makers novices, journeymen and experts. Based upon the above research, it was hypothesized that:

1. Although probabilistic in nature, the recommender will promote confidence and be used to improve general decision quality (i.e. reduce errors) by novices.
2. Among more experienced decision makers, the probabilistic recommender will be used to enhance decision quality (i.e. reduce errors) as contextual complexity (risk and time pressure) increases.

3. Experts will use the recommender to improve longrun decisions (i.e. achieve more wins), due to their strategic focus.

4. Deductive logic ability should promote the quality of decisions (i.e. reduce errors) among novices and journeymen but not experts.

\section{METHOD}

\section{Participants}

Eighty-four subjects participated in this study and included undergraduates, postgraduates and university research staff. Participation was voluntary and independent of course or work credit. All participants received \$6 payment, which is the standard rate for School of Psychology experiments. Participants were assigned to one of three mutually exclusive groups (novices, journeymen or experts) according to their level of decision-making expertise. Novices $(n=41)$ were students drawn from an undergraduate $2^{\text {nd }}$ year Psychology class. Journeymen $(n=$ 24) comprised students and professionals who had either a graduate or postgraduate degree that was not a PhD. Experts $(\mathrm{n}=19)$ were students and professionals who had attained a $\mathrm{PhD}$ or were studying for one.

\section{Apparatus and Task}

Experience Scale: Participants completed a 5-point Likert scale that measured their lifetime experience with the card games 'Blackjack', '21' and 'Pontoon'. Scale points ranged from ' 1 ' none to ' 5 ' extensive. This measure was obtained to determine whether card game experience was a potentially confounding variable.

Deductive Logic Ability Test: Subjects also completed a commercially available deductive logic ability test - Verbal Critical Reasoning VA3 [34]. This instrument is a timed paper and pencil test that requires 30 minutes to complete.

Blackjack Computer Program: Participants played a 30minute custom-designed computer simulation of a simplified version of the card game, 'Blackjack', which included an online recommender designed to minimize losses.

At the beginning of each hand, a blank screen was displayed. Subjects were then instructed to "place their bet" by the computer program. Subjects depressed a numeric key on the keyboard to indicate their choice of bet size with a minimum of 1 and a maximum of 9. Two cards were then dealt to the participant and the dealer (the dealer was the computer program). Card totals for both the dealer and the participant were calculated by the computer program and instantly displayed next to their cards. Participants were then asked whether or not they would like another card. Participants could either press a key to accept another card or not respond at all. Participants could ask for as many cards as they wished. The outcome of the hand was then displayed in the middle of the computer screen and the number of house points with which the subject had selected to play were then added to, or subtracted from, participants' 
cumulative total. The cumulative total could be either a negative or positive value.

The knowledge-based recommender dispensed advice according to the BASIC strategy. The principles underpinning this strategy have been derived from millions of computer simulations of the Blackjack game and, if followed, ensure "the highest quality of blackjack play" [35]. To provide individualized recommendations to the player, the recommender combined information on the cards currently held by the player and the dealer. Based on this information, participants were 'advised to hit' (i.e. ask for another card) or 'advised to stand' (i.e. refrain from asking for another card). However, the advice was probabilistic in nature as the cards that were dealt by the computer were random.

\section{Design}

This study used a within subjects $2 \times 2 \times 2$ time pressure by risk by recommender support design, with expertise included as a between subjects' factor. Each of the three independent variables comprised two levels: time stress was either high or low ( 1 second $v s 2$ second duration to reach a decision); stakes were either high or low (house points multiplied by $10 v s$ 2); and the decision aid was either activated or not. The order of the experimental conditions were randomly assigned and presented by the computer program. Subjects played 20 hands per condition and 160 hands in total.

Time pressure, or the time to register a response, was internally controlled by the pace of the computer program. The stakes level was denoted by either a green screen (low stakes) or a blue screen (high stakes).

Three dependent variables were used: average bet size, the total number of errors according to the BASIC strategy, and the total wins. The average bet was used as an index of confidence. Two aspects of decision performance were measured: total errors were an indicator of the quality of decision outcomes while total wins represented strategic outcomes.

\section{Procedure}

The rules of the blackjack game were explained to all participants. Participants were instructed that the recommender would be available on a proportion of trials. However, due to the uncertainty of the blackjack game, they were told that the advice was probabilistic in nature, meaning that sometimes its advice would be inaccurate. Participants were also told that they were free to follow or ignore the advice. Participants completed a consent form and the blackjack experience scale. They then undertook the blackjack task followed by the deductive logic test.

\section{RESULTS}

\section{Statistical Analyses}

In the following analyses, the focus was on the effect of contextual factors (risk and time pressure) on the use of a probabilistic, knowledge-based recommender among three groups of decision makers (novices, journeymen and experts). Data were analyzed with repeated measures analysis of variance (ANOVA) to examine the effects of manipulations on the average bet size (confidence), error commission (decision quality) and wins (strategic outcomes). Pearson's correlation was used to assess the association between deductive logic ability (VA3 scores) and decision quality (error commission). Finally, a KruskallWallis test was used to examine group differences in blackjack experience.

\section{Blackjack Experience}

The sample as a whole had a moderate amount of lifetime Blackjack experience (mode and median $=3$ ). Kruskall-Wallis test results revealed that blackjack experience did not differ significantly among the three expertise groups ( $>$ >05). Therefore, group differences reported in the following analyses were likely to be due to the study variables rather than differences in Blackjack experience.

\section{Average Bet Size (Confidence)}

The effect of the recommender on confidence levels was examined. Confidence levels were determined behaviorally, that is, by the size of the average bet: a relatively larger bet indicated greater confidence and a lower bet indicated lower confidence. A behavioural index of confidence is likely to be more accurate than self-report because it measures 'confidence in action'. In all of the following analyses, a comparison was made between assisted decision making (i.e. the recommender was available) and unassisted decisionmaking (i.e. the recommender was unavailable).

Table 1. Average Bet Size (Confidence) - Means \& Standard Deviations for Main Effects

\begin{tabular}{|l|c|c|c|c|c|c|c|c|}
\hline & \multicolumn{2}{|c|}{ Novices } & \multicolumn{2}{c|}{ Journeymen } & \multicolumn{2}{c|}{ Experts } & \multicolumn{2}{c|}{ Total Sample } \\
\hline \hline Recommender & Off & On & Off & On & Off & On & Off & On \\
Mean & 4.85 & 5.15 & 6.15 & 6.05 & 5.24 & 5.12 & 5.41 & 5.44 \\
(S.D.) & $(2.10)$ & $(2.04)$ & $(2.15)$ & $(2.26)$ & $(2.24)$ & $(2.15)$ & $(2.21)$ & $(2.15)$ \\
\hline Risk level & Low & High & Low & High & Low & High & Low & High \\
Mean & 5.25 & 4.74 & 6.44 & 5.76 & 5.44 & 4.91 & 5.71 & 5.14 \\
(S.D.) & $(1.89)$ & $(2.25)$ & $(2.02)$ & $(2.39)$ & $(1.96)$ & $(2.43)$ & $(2.01)$ & $(2.35)$ \\
\hline Time pressure & Low & High & Low & High & Low & High & Low & High \\
Mean & 5.29 & 4.70 & 6.52 & 5.68 & 5.33 & 5.03 & 5.71 & 5.14 \\
(S.D.) & $(2.17)$ & $(1.98)$ & $(2.11)$ & $(2.30)$ & $(2.28)$ & $(2.11)$ & $(2.23)$ & $(2.13)$ \\
\hline
\end{tabular}


Table 2. Average Bet Size (Confidence) - ANOVA Results

\begin{tabular}{|c|c|c|c|c|c|c|c|c|}
\hline \multirow{2}{*}{ ANOVAs } & \multicolumn{2}{|c|}{$\begin{array}{c}\text { Novices } \\
\mathrm{n}=\mathbf{4 1}\end{array}$} & \multicolumn{2}{|c|}{$\begin{array}{c}\begin{array}{c}\text { Journeymen } \\
\mathbf{n}=\mathbf{2 4}\end{array} \\
\end{array}$} & \multicolumn{2}{|c|}{$\begin{array}{c}\text { Experts } \\
\mathrm{n}=19\end{array}$} & \multicolumn{2}{|c|}{$\begin{array}{c}\text { Total Sample } \\
\mathrm{n}=\mathbf{8 4}\end{array}$} \\
\hline & Sig & Partial eta $^{2}$ & Sig & Partial eta $^{2}$ & Sig & Partial eta $^{2}$ & Sig & Partial eta ${ }^{2}$ \\
\hline Recommender x Risk & NS & .03 & NS & .06 & NS & .00 & NS & .00 \\
\hline Recommender $\mathrm{x}$ Time & NS & .02 & NS & .00 & NS & .11 & NS & .03 \\
\hline Recommender x Group & - & - & - & - & - & - & NS & .06 \\
\hline Risk $x$ Time & $\mathrm{p}<.001$ & .29 & $\mathrm{p}<.05$ & .20 & $\mathrm{p}<.05$ & .22 & $\mathrm{p}<.001$ & .19 \\
\hline Risk x Group & - & - & - & - & - & - & NS & .00 \\
\hline Time x Group & - & - & - & - & - & - & NS & .05 \\
\hline Recommender $x$ Risk $x$ Time & NS & .00 & NS & .01 & NS & .11 & NS & .03 \\
\hline
\end{tabular}

Novices bet significantly more when the recommender was available compared to when it was unavailable $F(1,40)$ $=5.68, \mathrm{p}<.05$ (see Table 1). The effect size was moderately large (partial eta squared $=0.12$ ). These results suggest that the availability of the probabilistic recommender increased novices' decision confidence. However, the recommender did not exert a significant effect on the confidence levels of journeymen or experts. None of the two-way or three-way interactions were significant (see Table 2).

\section{Error Commission (Decision Quality)}

Although only moving towards significance, the availability of the recommender reduced error commission for all three groups. The effect of the recommender on error commission was influenced by contextual variables, with the relationship becoming more complex as expertise increased. Overall, availability of the recommender only tended to increase participants' decision accuracy.

Among novices, availability of the recommender tended to result in fewer decision errors $F(1,40)=3.67, \mathrm{p}=0.06$ (see Table 3). The effect size was moderate (partial eta ${ }^{2}=$ $.08)$.

Results for the 2-way and 3-way interactions are displayed in Table 4.

Among journeymen, a more complex two-way interaction between availability of the recommender and risk level was observed, $F(1,23)=3.50, \mathrm{p}=0.07$. Specifically, as shown in Fig. (1), compared to unassisted decision making, availability of the recommender in a high risk situation tended to improve decision accuracy. The effect size was large (partial eta $\left.{ }^{2}=.22\right)$.

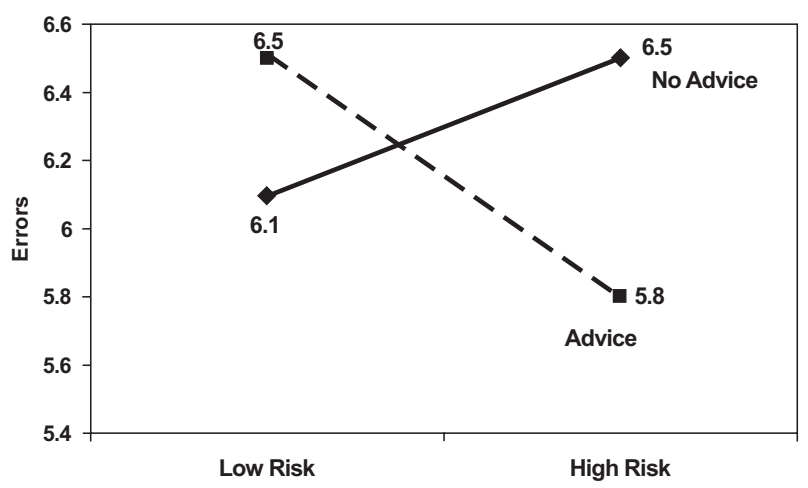

Fig. (1). Journeymen: the effect of the recommender and risk level on performance (error commission).

Among experts, a very complex 3-way interaction $F(1,18)=3.97, \mathrm{p}=0.06$ was found. In a high risk situation, availability of the recommender was more likely to improve decision accuracy when time pressure was high (compared to unassisted decision making). In a low risk situation, availability of the recommender was more likely to improve decision accuracy when time pressure was low (compared to unassisted decision making) (see Figs. 2, 3). The effect size was large (partial eta $\left.{ }^{2}=.18\right)$.

Table 3. Error Commission (Decision Quality) - Means \& Standard Deviations for Main Effects

\begin{tabular}{|l|c|c|c|c|c|c|c|c|}
\hline & \multicolumn{2}{|c|}{ Novices } & \multicolumn{2}{c|}{ Journeymen } & \multicolumn{3}{c|}{ Experts } & \multicolumn{2}{c|}{ Total Sample } \\
\hline \hline Recommender & Off & On & Off & On & Off & On & Off & On \\
Mean & 6.06 & 5.54 & 6.29 & 6.15 & 6.31 & 6.11 & 6.22 & 5.94 \\
(S.D.) & $(2.24)$ & $(2.29)$ & $(2.37)$ & $(2.25)$ & $(2.08)$ & $(2.13)$ & $(2.25)$ & $(2.35)$ \\
\hline Risk level & Low & High & Low & High & Low & High & Low & High \\
Mean & 5.96 & 5.65 & 6.29 & 6.15 & 6.46 & 5.97 & 6.23 & 5.92 \\
(S.D.) & $(2.32)$ & $(2.20)$ & $(2.62)$ & $(2.34)$ & $(2.40)$ & $(1.80)$ & $(2.43)$ & $(2.17)$ \\
\hline Time pressure & Low & High & Low & High & Low & High & Low & High \\
Mean & 5.18 & 6.42 & 5.80 & 6.64 & 5.68 & 6.75 & 5.55 & 6.60 \\
(S.D.) & $(2.17)$ & $(2.35)$ & $(2.33)$ & $(2.63)$ & $(2.13)$ & $(2.07)$ & $(2.23)$ & $(2.37)$ \\
\hline
\end{tabular}


Table 4. Error Commission (Decision Quality) - ANOVA Results

\begin{tabular}{|c|c|c|c|c|c|c|c|c|}
\hline \multirow{2}{*}{ ANOVAs } & \multicolumn{2}{|c|}{$\begin{array}{c}\text { Novices } \\
\mathrm{n}=41\end{array}$} & \multicolumn{2}{|c|}{$\begin{array}{c}\text { Journeymen } \\
\mathbf{n}=\mathbf{2 4}\end{array}$} & \multicolumn{2}{|c|}{$\begin{array}{c}\text { Experts } \\
n=19\end{array}$} & \multicolumn{2}{|c|}{$\begin{array}{c}\text { Total Sample } \\
n=84\end{array}$} \\
\hline & Sig & Partial eta $^{2}$ & Sig & Partial eta $^{2}$ & Sig & Partial eta $^{2}$ & Sig & Partial eta $^{2}$ \\
\hline Recommender x Risk & NS & .01 & $\mathrm{p}=.07$ & .13 & NS & .00 & NS & .00 \\
\hline Recommender $x$ Time & NS & .01 & NS & .08 & NS & .01 & NS & .01 \\
\hline Recommender x Group & - & - & - & - & - & - & NS & .01 \\
\hline Risk $x$ Time & $\mathrm{p}=.05$ & .09 & $\mathrm{p}<.05$ & .22 & NS & .09 & $\mathrm{p}<.01$ & .12 \\
\hline Risk x Group & - & - & - & - & - & - & NS & .00 \\
\hline Time x Group & - & - & - & - & - & - & NS & .01 \\
\hline Recommender $x$ Risk $x$ Time & NS & .00 & NS & .00 & $\mathrm{p}=.06$ & .18 & NS & .02 \\
\hline
\end{tabular}

\section{Wins (Strategic Outcomes)}

Among journeymen, a simple main effect was found for the recommender $F(1,23)=4.79, p<0.05$. Availability of the recommender significantly impaired journeymen's strategic performance - fewer wins were attained (see Table 5). The effect size was large (partial eta $\left.{ }^{2}=.17\right)$.

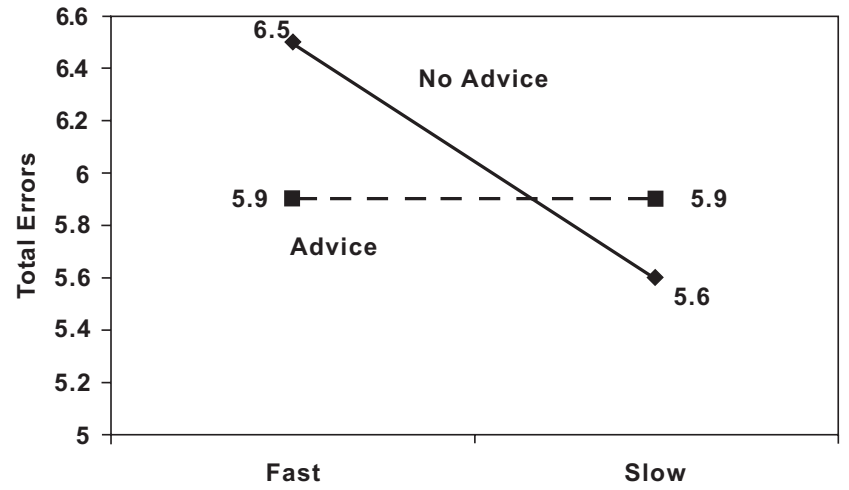

Fig. (2). Experts: high risk environment - the effect of recommender use and time pressure on performance (error commission).

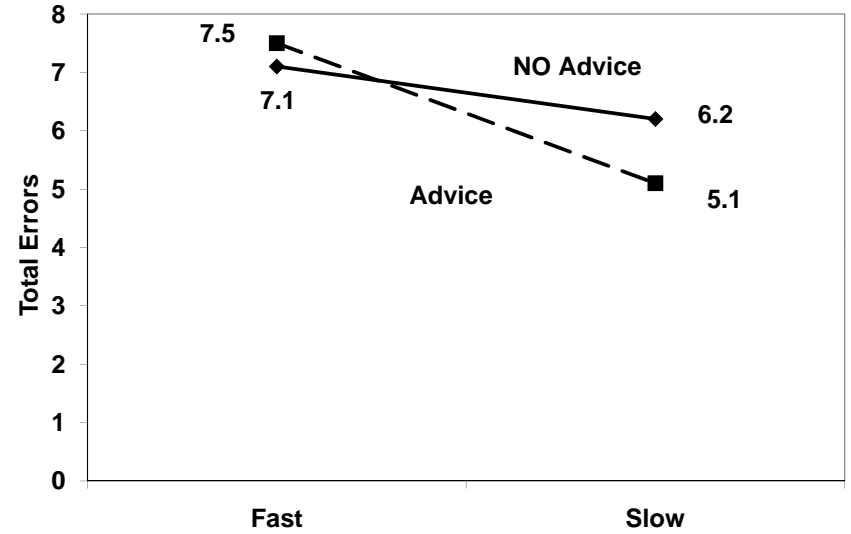

Fig. (3). Experts: low risk environment - the effect of recommender use and time pressure on performance (error commission).
A significant two-way interaction between availability of the recommender and expertise was observed, $F(1,81)=$ 3.21, $p<0.05$. In particular, as revealed in Fig. (4), availability of the recommender enhanced experts' performance, impaired journeymen's performance and exerted little effect on novices' outcomes. The effect size was moderate (partial eta $\left.{ }^{2}=.07\right)$. The three-way interaction was not significant (see Table 6).

\section{Deductive Logic Ability and Decision Quality}

To examine the association between individual differences in deductive logic ability and decision quality, the correlation between deductive logic ability and total errors on the Blackjack task was calculated. A significant negative correlation was found for the total sample $(r=-.30$, $\mathrm{p}<0.01, \mathrm{n}=84)$. Thus, decision-makers with higher levels of deductive logic committed fewer errors. The association was strongest for journeymen $(\mathrm{r}=-.60, \mathrm{p}<0.01, \mathrm{n}=24)$ suggesting a strong analytical approach to decision making, possibly due to their research training. Among novices, there was a marked tendency for those with higher levels of logic to commit fewer errors $(\mathrm{r}=-.23, \mathrm{p}=0.07, \mathrm{n}=41)$ indicating that they are still developing their skills. Among experts, the correlation between logic and errors was not significant $(r=$ $.18, \mathrm{p}>0.05, \mathrm{n}=19$ ) suggesting that other factors may influence decision quality.

\section{DISCUSSION}

To operate successfully in real-time e-markets, knowledge-based recommenders may become indispensable. This study investigated the effects of risk level and time pressure on the use of a probabilistic, knowledge-based recommender by decision makers with three levels of expertise (novices, journeymen and experts) using a laboratory-based approximation of a real-time e-market decision environment. Because the recommender acted in an advisory capacity, rather than merely recommending items of interest, it represented a second-generation knowledgebased recommender.

The blackjack task was selected as a close approximation of key aspects of e-commerce activities, such as e-auctions. Real-time e-auctions are dynamic, time-pressured events in which risk may be high (e.g. real estate or antique auctions) 
Table 5. Wins (Strategic Outcomes - Means \& Standard Deviations for Main Effects

\begin{tabular}{|l|c|c|c|c|c|c|c|c|}
\hline & \multicolumn{2}{|c|}{ Novices } & \multicolumn{2}{c|}{ Journeymen } & \multicolumn{2}{c|}{ Experts } & \multicolumn{2}{c|}{ Total Sample } \\
\hline \hline Recommender & Off & On & Off & On & Off & On & Off & On \\
Mean & 7.04 & 7.06 & 6.86 & 6.15 & 6.61 & 7.14 & 6.84 \\
(S.D.) & $(2.29)$ & $(2.30)$ & $(2.21)$ & $(2.07)$ & $(2.10)$ & $(2.27)$ & $(2.23)$ & $(2.61)$ \\
\hline Risk level & Low & High & Low & High & Low & High & Low & High \\
Mean & 6.84 & 7.26 & 6.68 & 6.33 & 6.65 & 7.10 & 6.72 & 6.90 \\
(S.D.) & $(2.35)$ & $(2.25)$ & $(2.05)$ & $(2.23)$ & $(2.32)$ & $(1.87)$ & $(2.26)$ & $(2.20)$ \\
\hline Time pressure & Low & High & Low & High & Low & High & Low & High \\
Mean & 7.06 & 7.03 & 6.74 & 6.28 & 6.84 & 6.92 & 6.88 & 6.74 \\
(S.D.) & $(2.18)$ & $(2.42)$ & $(2.14)$ & $(2.15)$ & $(1.93)$ & $(2.29)$ & $(2.34)$ & $(2.12)$ \\
\hline
\end{tabular}

Table 6. Wins (Strategic Outcomes - ANOVA Results

\begin{tabular}{|c|c|c|c|c|c|c|c|c|}
\hline ANOVAs & Sig & Partial eta $^{2}$ & Sig & Partial eta $^{2}$ & Sig & Partial eta $^{2}$ & Sig & Partial eta ${ }^{2}$ \\
\hline Recommender x Risk & NS & .01 & NS & .00 & NS & .00 & NS & .01 \\
\hline Recommender x Time & NS & .00 & NS & .02 & NS & .06 & NS & .02 \\
\hline Risk x Group & - & - & - & - & - & - & $\mathrm{p}=.05$ & .00 \\
\hline Time x Group & - & - & - & - & - & - & NS & .02 \\
\hline Recommender $x$ Risk x Time & NS & .00 & NS & .03 & NS & .10 & NS & .01 \\
\hline
\end{tabular}

or low (e.g. household item auctions). Other key e-auction characteristics such as uncertainty, multiple bidders, immediate feedback (i.e. amount bid and accepted, and decision outcome) were also present in the Blackjack task. In addition, the dynamic and unfolding nature of the Blackjack task, in which previous decisions impacted on future decisions and outcomes, more accurately emulated e-market environments. Due to the uncertainty inherent in e-auctions, a probabilistic, knowledge-based recommender was provided in a proportion of trials to compare its effect on decision confidence and outcomes, compared to unassisted decisionmaking. The knowledge-based probabilistic recommender provided personalized advice based upon the player's and dealer's card totals according to an optimum decision strategy (i.e. BASIC).

Research into the effect of expertise on recommender use usually employs tasks specific to the users' domain of expertise [16,19]. The present study used a semi-familiar task (i.e. participants had a moderate amount of experience with blackjack but none were professionals). Participants were classified according to their expertise in decisionmaking, which is a generic, transferable skill. The mix of a semi-familiar task and generic decision making expertise was selected to provide a closer analogue with e-bidders operating in an e-market situation. That is, e-bidders are unlikely to be professionals in the auction industry but they will have different levels of decision-making expertise. Level of education was also deemed suitable due to its

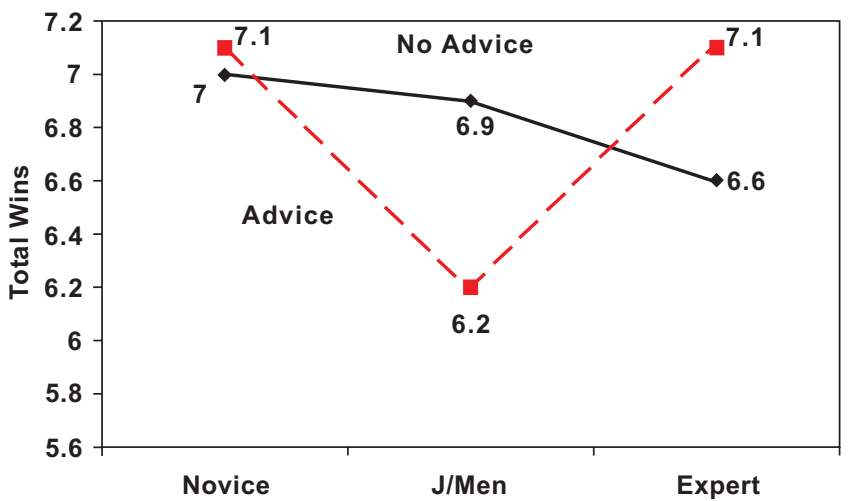

Fig. (4). The effect of the recommender and decision-maker expertise on performance (Wins).

association with successful decision-making and the research-related component of web-based e-commerce activities.

The effect of the recommender on decision confidence and performance differed according to the type of outcome (errors or wins), contextual complexity and the decision maker's expertise. Availably of the probabilistic recommender significantly increased the confidence of novices only. Klein and Jiang [36] also found that decision aids fostered a positive response among novices who reported a 'warmth of reaction'. However, among 
journeymen and experts the recommender did not improve confidence. It may be that, in the face of incorrect advice, experienced participants were more cognizant of the potential for the recommender to be inaccurate and, therefore, did not trust its advice. Nevertheless, availability of the recommender improved the decision making performance of all participants, although the circumstances differed according to their level of expertise.

Among novices, simple main effects for recommender use and error commission were found, although the effect represented a marked tendency only $(\mathrm{p}=.06)$. Error avoidance is typical of novice performance [24]. Therefore, novices' reliance on the knowledge-based recommender to avoid errors most likely reflects their developmental level. In contrast, journeymen's and experts' tendency to use the recommender's advice to avoid decision errors was related to task complexity. Compared to unassisted decision making, availability of the recommender resulted in lower error commission among journeymen when time pressure was high, and among experts' when both risk and time pressure were high. Due to the potential for greater loss in a high risk situation, journeymen may have relied on the recommender to reduce uncertainty [37]. Experts may have used the recommender to reduce uncertainty in a high risk situation but also to alleviate the greater cognitive load and effort [11] associated with processing the same amount of information in a shorter period of time.

These results are consistent with the theory of technological dominance [22], which posits that intelligent decision aid use by experienced decision-makers is mediated by task complexity. Gino and Moore [38] found that decision makers assigned a greater weight to advice when tasks were difficult. Thus, it appears that the more experienced decision makers (i.e. journeymen and experts) used the recommender to extend their cognitive capabilities which may have been stretched by higher task demands. While time pressure augments the effects of cognitive limitations [14] it also increases the information processing load on working memory [13]. Therefore, experts may also have relied on the recommender to reduce cognitive effort and thereby improve decision accuracy [11].

The significant group differences in the use of the recommender to improve strategic outcomes (i.e. wins) most likely reflected users' different experience-related perspectives. Despite its sometimes inaccurate advice, experts used the probabilistic recommender to increase their wins. Due to greater experience, experts may be better equipped to accommodate the sometimes inaccurate advice dispensed by the recommender [39]. They may also be better at evaluating the usefulness and importance of advice when making risky decisions [40]. Experts' use of the recommender to increase wealth (i.e. achieve more wins) but not for error avoidance suggests a strategic focus on the long-run. These results are noteworthy because decision makers tend to adopt a shortrun rather than a long-run focus as uncertainty increases [41]. The present study found that provision of a recommender promoted a long-run or strategic focus, at least among experts.

In contrast, availability of the recommender damaged journeymen's performance, resulting in fewer wins. There are two possible, inter-related explanations for this result.
According to Anderson's three stage model of skill acquisition [42] journeymen are at the second 'knowledge compilation' stage. Knowledge compilation is concerned with how declarative knowledge (i.e. facts) is used in problem solving. This suggests an analytical approach to problem solving. Journeymen may be trying to integrate the extra (and sometimes conflicting) advice dispensed by the recommender with their own judgment. This may have placed greater information processing demands on working memory, resulting in impaired performance through cognitive overload [13]. The large and significant correlation between deductive logic ability and error commission found among journeymen supports this interpretation.

Availability of the recommender had little effect on novice performance. Novices may have appraised the advice as lower quality, due to its inaccuracies, and discounted it [43]. A relative lack of experience may have reduced tolerance for imperfect or probabilistic advice [39]. Chau, Phillips and Von Baggo [44] found that, in the face of losses, use of a probabilistic decision aid was abandoned and users reverted to their own personalized strategies. It may be that the probabilistic nature of the recommender, coupled with the uncertain nature of the decision environment, prompted novices to estimate that their own (guessing) strategies were as effective as the recommender's advice.

An interesting anomaly surfaced - although experts did not demonstrate confidence in the probabilistic recommender by increasing their bet size, they used the recommender's advice to increase their wealth (i.e. achieve more wins). In an uncertain and dynamic environment, experts may be able to accommodate inaccurate advice due to their strategic focus but may not trust the recommender's advice, due to its potential to be inaccurate. In contrast, novices were significantly more confident when the recommender was available, but they only tended to use it to improve decision quality (i.e. reduce errors) most likely due to its probable versus absolute accuracy.

Deductive logic ability was deemed the most suitable cognitive skill to assess decision making quality in the Blackjack task because logic ability is an implicit construct in most decision making models, which assume that the decision maker is a rational being $[12,45]$. This suggests that decision errors may be related to deficiencies in reasoning. Furthermore, the association between reasoning and errors may be attenuated by level of expertise - novice performance is characterized by explicit, rule-based reasoning while expert performance is characterized by an abstract understanding of deeper principles [24]. In addition, knowledge-based recommenders are constructed according to deductive 'if-then' principles to form conclusions about how information is related [46], therefore, deductive logic ability has greater congruence with a task that examines recommender use. Knowledge-based recommenders enhance users' decision quality by expanding their cognitive abilities [11], therefore, a measure of users' baseline cognitive abilities may assist with obtaining a closer skill match between the cognitive skill of the user and recommender [46].

Although logic is an implicit construct in decision theory [45], little research has been conducted on the influence of individual differences in logic ability on decision making 
[47]. The present study provided empirical support for the link between logic ability and decision making quality decision makers with higher levels of deductive logic committed significantly fewer errors, thus reaching better quality decisions. These results also support the contention of Johnson et al., [25] that decision errors are best ascribed to failures of reasoning. Furthermore, although time pressure results in a significantly greater number of logical errors [48], the present study found that higher deductive logic ability ameliorates the deleterious effects of time pressure. It may be that individuals with higher levels of deductive logic may be less prone to errors due to faster processing of pertinent information.

The present study also found that the link between logic and error commission was attenuated by decision-makers' expertise level. Consistent with models of expertise, logic ability was correlated with errors among less experienced decision makers (i.e. novices and journeymen) but not among experts. Cognitive ability is related to skill acquisition in the early stages of development $[28,29]$ while deliberate, focused practice predicts expert performance [31].

Previous research has reported inconsistent results on recommenders' ability to improve decision quality and accuracy [11], and that experts generally abandon their use due to overconfidence $[20,21]$. These results extend current research knowledge because they show that experts use a probabilistic recommender to improve decision quality when task demands are high, and to improve strategic outcomes in high risk and time-pressured environments. Furthermore, they also indicate that journeymen's strategic performance is damaged by probabilistic recommenders probably due to a cognitive mismatch and journeymen's heavy reliance on their own reasoning skills. Finally, these results add to the scant research on the effects of time pressure and risk on the use of probabilistic recommenders $[14,16]$.

Knowledge-based recommenders which represent the user in e-markets and make recommendations based on product information, market conditions and user attributes (not simply preference profiles) may be thought of as second generation recommenders. Results from the present study suggest that there is a place for recommenders in real-time, on-line auctions provided they are tailored to fit end-user profiles. Since e-commerce places an organization's competitors just another click away [1], 'word of mouse' may become the predominant market force of the future [8]. To ensure that e-organizations' reputations are enhanced, or at least maintained, the use of knowledge-based recommenders tailored and matched to e-customers' requirements may foster customer loyalty and satisfaction. Customer loyalty may become an even more precious commodity with the advent of location aware technologies, which can target potential customers via their mobiles [4951], suggesting another electronic avenue for participation in e-commerce activities. Seeking advice from colleagues and friends is a common feature of everyday decision making [21]. As e-commerce becomes more pervasive, seeking advice from a recommender may also become integral to decision-making, therefore, a well-matched recommender may encourage the user to regard the aid as an electronic colleague or agent [23].

\section{Limitations}

A potential limitation of this study was that the observed improvements in decision making performance when the recommender was available could potentially be ascribed to other confounds. Perhaps the display of this aid, for example, reduced anxiety and thus improved performance. Future research, therefore, should vary the validity of information the recommender offers. If this aid is utilized, the accuracy of decisions should depend on the validity of information the aid provides. There may have been a potential carry-over, due to practice effects, from using a within-subjects design. However, this effect was minimized because experimental conditions were randomly assigned by the computer.

\section{CONCLUSIONS}

Knowledge-based probabilistic recommenders which are command-based can confer benefit in an e-market environment. Expert decision-makers may benefit the most from a probabilistic recommender, particularly if task demands are high (i.e. high risk and time pressure) or when making strategic decisions. Novice decision-makers may also benefit from a probabilistic recommender to improve the overall quality of their decisions. However, probabilistic recommenders interfere with the strategic performance of users with an intermediate level of decision-making experience. Therefore, user profiles based on decisionmaking expertise may assist with matching the skill level of users and recommenders.

\section{REFERENCES}

[1] Nielsen J. Designing web usability. Indianapolis: New Riders Publishing 2000

[2] Towle B, Quinn C. Knowledge based recommender systems using explicit user models. Knowledge-based electronic markets: Paper from AAAI, Technical Reports WS-00-04, 74-77, 2000.

[3] Burke R. Knowledge-based recommender systems. In: Daily JE, Kent A, Lancour H, Eds. The Encyclopedia of Library and Information Science 2000; vol. 69(Suppl 32).

[4] Montaner M, Lopez B, De La Rosa JL. A taxonomy of recommender agents on the internet. Artific Intell Rev 2003; 19: 45.

[5] Schafer JB, Konstan J, Reidl J. Recommender systems in ecommerce. In EC '99: Proceedings of the $1^{\text {st }}$ ACM Conference in Electronic Commerce. Denver, CO 1999; pp. 158-66.

[6] Hill W, Stead L, Rosenstein M, Furnas G. Recommending and evaluating in a virtual community of use. In Proceedings of ACM CHI'95 Conference on Human factors in Computing Systems 1995; pp. 194-201.

[7] Fasli M. On agent technology for e-commerce: trust, security and legal issues. Knowl Eng Rev 2007; 22: 3-35.

[8] De Valack K, van Bruggen GH, Wierenga B. Virtual communities: a marketing perspective. Decis Support Syst 2009; 47: 185-203.

[9] Arnold V, Clark N, Collier PA, Leech SA, Sutton SG. Explanation provision and use in an intelligent decision aid. Intell Syst Account Finance Manag 2004; 12: 5-27.

[10] Sieck WR, Arkes HR. The recalcitrance of overconfidence and its contribution to decision aid neglect. J Behav Decis Making 2005; 18: 29-53.

[11] Chu PC, Spires EE. The joint effects of effort and quality on decision strategy choice with computerized decision aids. Decis Sci 2000; 31: 259-92.

[12] Simon HA. A behavioral model of rational choice. Q J Econ 1955; 69: 99-118.

[13] Timmermans D, Vlek C. Multi-attribute decision support and complexity: an evaluation and process analysis of aided versus unaided decision making. Acta Psychol 1992; 80: 49-65.

[14] Chu PC, Spires EE. Does time constraint on users negate the efficacy of decision support systems? Organ Behav Hum Decis Process 2001; 85: 226-49. 
[15] Todd P, Benbasat I. Inducing compensatory information processing through decision aids that facilitate effort reduction: an experimental assessment. J Behav Decis Making 2000; 13: 91-106.

[16] Sarter NB, Schroeder B. Supporting decision making and action selection under time pressure and uncertainty: the case of in-flight icing. Hum Factors 2001; 43: 573-83.

[17] Vicente KJ. Less is (sometimes) more in cognitive engineering: the role of information technology in improving patient health safety. Qual Saf Health Care 2003; 12: 291-4.

[18] Dexter F, Willemsen-Dunlap A, Lee JD. Operating room managerial decision-making on the day of surgery with and without computer recommendations [Abstract]. Anesth Analg 2007; 105: 419-29.

[19] Whitecotton SM. The effects of experience and a decision aid on the slope, scatter, and bias of earnings forecasts. Org Behav Hum Decis Process 1996; 66: 111-21.

[20] Arkes HR, Dawes RM, Christensen C. Factors influencing the use of a decision rule in a probabilistic task. Org Behav Hum Decis Process 1986; 37: 93-110.

[21] Yaniv I. Receiving other people's advice: influence and benefit. Org Behav Hum Decis Process 2004; 93: 1-13.

[22] Arnold V, Sutton SG. The theory of technology dominance: Understanding the impact of intelligent decision aids on decision makers' judgments. Adv Accounting Behav Res 1998; 1: 175-94.

[23] Arnold V, Collier PA, Leech SA, Sutton SG. The impact of intelligent decision aids on expert and novice decision makers' judgment processes. Paper presented at the American Accounting Association Auditing Section Midyear Conference 1998.

[24] Dreyfus HL, Dreyfus SE. Mind over machine. Oxford: Blackwell Science 1986

[25] Johnson PE, Graziole S, Jamal K, Zualkernan IA. Success and failure in expert reasoning. Org Behav Hum Decis Process 1992; 53: 173-203.

[26] Parsons LM, Osherson D. New evidence for distinct right and left brain systems for deductive versus probablistic reasoning. Cereb Cortex 2001; 11: 954-65.

[27] Carroll JB. Factor analysis since Spearman: where do we stand? What do we know? In: Kanfer R, Ackerman PL, Cudeck R, Eds. Learning and individual differences: abilities, motivation, and methodology. Hillsdale, NJ: Erlbaum 1989.

[28] Ruthsatz J, Detterman DK. An extraordinary memory: the case study of a musical prodigy. Intelligence 2003; 31: 509-18.

[29] Ruthschatz J, Detterman DK, Griscom WS, Cirullo BA. Becoming an expert in the musical domain: it takes more than just practice. Intelligence 2008; 36: 330-38.

[30] Charness N, Tuffiash M, Krampe R, Reingold E, Vasyukova E. The role of deliberate practice in chess expertise. Appl Cogn Psychol 2005; 19: 151-65.

[31] Ericsson EA, Krampe RT, Tesch-Romer C. The role of deliberate practice in the acquisition of expert performance. Psychol Rev 1993; 100: 363-406.

[32] O'Hare MA. An exploration of the validity and reliability of 'Managerial Reading Assessment' - a cognitive ability test. Masters Thesis. Palmerston North: Massey University 1999.
[33] Judge TA, Cable DM, Bougreau JW, Bretz Jr RD. An empirical investigation of the predictors of executive career success. Personnel Psychol 1995; 48: 485-519.

[34] SHL. Verbal Critical Reasoning VA3. UK: SHL Group 2000.

[35] Walker MB, Sturevska S, Turpie D. The quality of blackjack play in Australian casinos. Paper presented at the Sixth National Conference of the National Association for Gambling Studies, Freemantle, Western Australia 1995.

[36] Klein G, Jaing JJ. User perception of expert system advice. J Syst Softw 1999; 48: 155-61.

[37] Ter Huurne E, Gutteling JM. Information needs and risk perception as predictors of risk information seeking. J Risk Res 2008; 11: 84762.

[38] Gino F, Moore DA. Effects of task difficulty on use of advice. J Behav Decis Making 2007; 20: 21-35.

[39] Farrington-Darby T, Wilson JR. The nature of expertise. Appl Ergon 2006; 37: 17-32.

[40] Harvey N, Fischer I. Taking advice: accepting help, improving judgment and sharing responsibility. Org Behav Hum Decis Process 1997; 70: 117-33.

[41] Tyska T, Zielonka P, Dacey R, Sawicki, P. Perception of randomness and predicting uncertain events. Think Reason 2008; 14: $83-110$.

[42] Anderson JR. Acquisition of cognitive skill. Psychol Rev 1982; 89: 369-406.

[43] Yaniv I, Kleinberger E. Advice taking in decision making: egocentric discounting and reputation formation. Org Behav Hum Decis Process 2000; 83: 260-81.

[44] Chau AW, Phillips JG, Von Baggo KL. Departures from sensible play in computer blackjack. J Gen Psychol 2000; 127: 426-38.

[45] Keren G, deBruin WB. On the assessment of decision quality: Considerations regarding utility, conflict and accountability. In: Hardman D, Maachi L, Eds. Thinking: psychological perspectives on reasoning, judgment and decision making. Europe: John Wiley \& Sons Ltd 2003; pp. 347-63.

[46] Rowe AJ, Watkins PR. Beyond expert systems - reasoning judgment, and wisdom. Exp Syst Appl 1992; 4: 1-10.

[47] Joslyn S, Hunt E. Evaluating individual differences in response to time-pressured situations. J Exp Psychol Appl 1998; 4: 16-43.

[48] Evans JS, Curtis-Holmes J. Rapid responding increases belief bias: evidence for the dual process theory of reasoning. Think Reason 2005; 11:382-389.

[49] Aalto L, Göthlin N, Korhonen J, Ojala T. Bluetooth and WAP push based location-aware mobile advertising system. In MobiSys '04: Proceedings of the $2^{\text {nd }}$ international conference on Mobile systems, applications, and services 2004; pp. 49-58.

[50] Yang WS, Cheng HC, Dia JB. A location-aware recommender system for mobile shopping environments. Exp Syst Appl 2008; 34: 437-45.

[51] Yuan ST, Tsao YW. A recommendation mechanism for contextualized mobile advertising. Exp Syst Appl 2003; 24: 399414. 